\title{
Medical societies scramble to include disclosure on clinical guidelines
}

$\mathrm{D}$ espite the growing push toward full transparency in clinical guideline development, some Canadian medical societies continue to buck the trend, which some experts claim will ultimately erode the credibility of all guidelines.

"If we don't protect the process, none of them will be credible," says Dr. Allan Sniderman, professor of cardiology at the University of McGill in Montréal, Quebec, citing recent contraceptive guidelines from the Society of Obstetricians and Gynaecologists of Canada as "an egregious example" of guidelines completely lacking in transparency because they contain no disclosure of potential conflicts of interest (www.sogc .org/guidelines/documents/gui252CPG1 012E.pdf).

Although disclosure has become the accepted standard in guideline development, it also remains altogether common that authors have a relationship with industry (www.cmaj.ca/cgi/doi/10.1503 /cmaj.109-3757), which leads some to argue that there's a need for the creation of some form of central body to fund and coordinate guidelines development across the country (www.cmaj .ca/cgi/doi/10.1503/cmaj.109-3784).

Yet, despite the widespread move towards disclosure of industry ties, some societies, such as the Society of Obstetricians and Gynaecologists of Canada (SOGC), continue to release guidelines without unveiling conflicts.

For example, the society's recent guidelines on drospirenone and ethinyl estradiol, written by Dr. Robert Reid, professor of obstetrics and gynecology at Queen's University in Kingston, Ontario, and approved by the society's clinical practice gynecology committee, contained no disclosure. But a virtually identical document on the contraceptives was published months earlier by Reid out of a workshop conducted by the drug's manufacturer Bayer HealthCare, a subsidiary of Bayer AG,

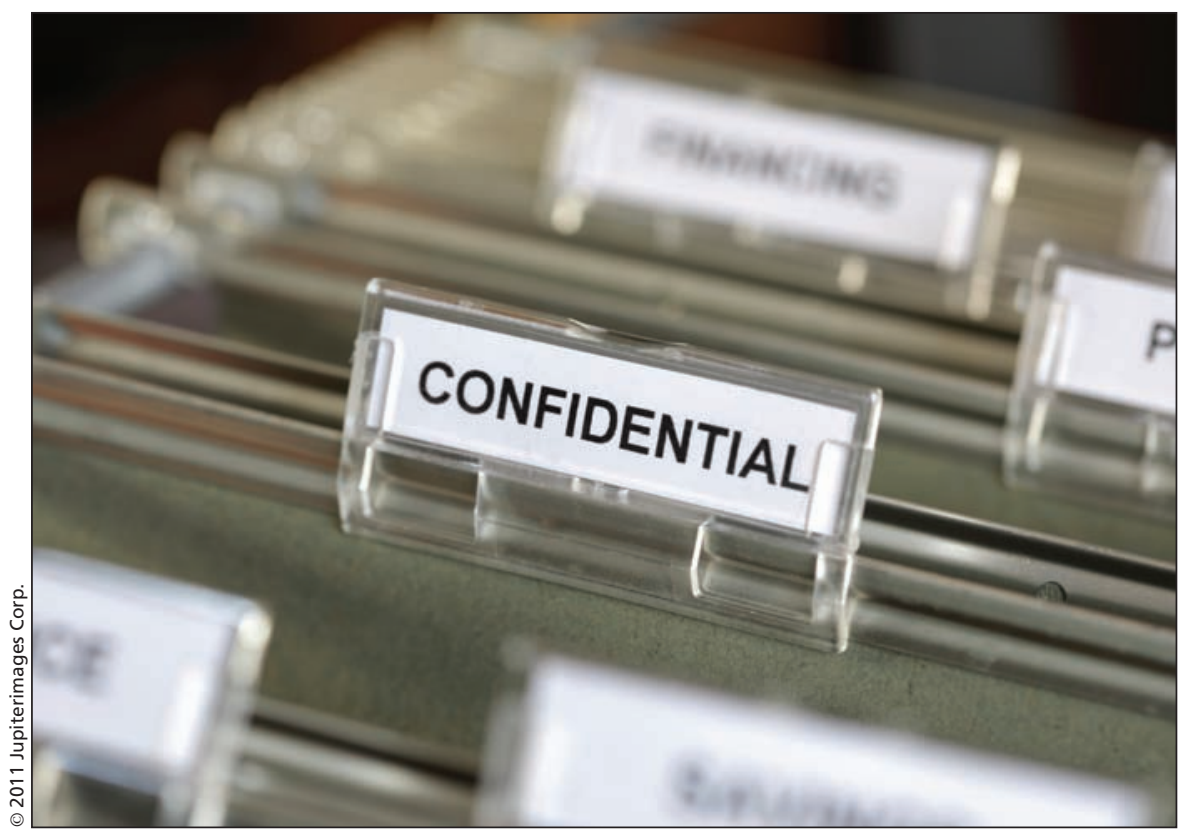

Some societies argue that they keep conflict of interest information confidential because the industry ties have no impact on the independence of clinical practice guidelines.

headquartered in Leverkusen, Germany (http://news.viva.vita.bayerhealthcare .com/uploads/tx_csrbayernews/consen sus_01.pdf).

The latter document indicated that the majority of the panel which crafted the workshop report "will, at one time or another, have received sponsorship and/or funding from one or more manufacturers of contraceptive drugs or products."

Why was at least some disclosure appropriate to the workshop report and none to the society's guidelines?

There's no need for disclosure, Dr. André B. Lalonde, the Society of Obstetricians and Gynaecologists of Canada's executive vice-president writes in an email. "While some members assume expert roles with pharmaceutical firms, it is understood that when they take part in the guideline development process, they do so as a subject matter expert, not as a spokesperson for a particular company or firm. ... I fail to see how one could perceive Dr. Reid as having 'conflicting interests'."

The contraceptive guidelines "did not come from" the drug company meeting, Lalonde says in defending the independence of the guidelines.

Reid, though, acknowledges that he is a consultant for Bayer and that there was a connection. "The reason the SOGC asked me to write the guideline is that they knew I had been to this meeting," he says. "That's really where I got my information."

The society is not alone when it comes to lack of disclosure. The Canadian Paediatric Society says it similarly does not automatically disclose conflicts of interest among its guideline panelists.

That's because "the vast majority of our statements have nothing to do with anything that would be of commercial interest," says Marie Adèle Davis, the society's executive director. "They are mostly about reminding kids not to smoke, using car seats, or breastfeeding."

Davis adds that the society's board of directors assesses individual contributors and the development process in general to determine if there was a conflict. "If they felt it should be dis- 
closed publicly in a guideline, it would be. But so far it hasn't come up."

Other Canadian medical societies appear more inclined toward disclosure. Recent rhinosinusitis guidelines from the Canadian Society of Allergy and Clinical Immunology contain a cryptic statement on competing interests (www .aacijournal.com/content/7/1/2).

Similarly, the Canadian Cardiovascular Society, in its 2010 atrial fibrillation guidelines, began incorporating an online link to disclosures (www.ccs guidelineprograms.ca/index.php?option $=$ com_content $\&$ view $=$ article $\&$ id $=126 \&$ Itemid=98).

As a part of a recent overhaul of its guideline processes, the Canadian Cardiovascular Society adopted an international standard for guidelines called GRADE (Grading of Recommendations Assessment, Development and Evaluation), explains Carolyn Pullen, the society's director of knowledge translation. "It forces transparency and conflict of interest disclosure."

"The stakes are high in cardiology because cardiologists are the biggest prescribers, period," Pullen says. "There's a lot of potential to sell a lot of drugs. And so it's really important we go the extra mile to demonstrate transparency and conflict of interest disclosure because the repercussions for the healthcare system, and a huge swath of the Canadian population and care providers is enormous."

Last year, the Canadian Thoracic Society released guidelines on chronic obstructive pulmonary disease, with a similar online table of author disclosures (www.respiratoryguidelines.ca/sites/all /files/COPD_COI_Pulmonary_Rehabili tation\%20_July_2010.pdf), intended to be a "benchmark" for future guidelines.

"The chair monitored conflict of interest statements from committee members every three months over the 12 month guideline development process and updated them if necessary," says Janet Sutherland, director of the society.

When asked about two subsequent society guidelines that did not include disclosure (one on chronic thromboembolic pulmonary hypertension and another on sleep-disordered breathing), Sutherland identified this as an administrative oversight. "This is the new standard we are adopting. ... There was a gap in our process that has now been rectified and the tables are now posted on our guidelines website" (www.respiratoryguidelines.ca /sites/all/files/CTEPH_Guideline_COI _2010_0.pdf and www.respiratoryguide lines.ca/sites/all/files/Sleep_Apnea_COI _February_2011.pdf).
Sniderman notes that decisions to disclose are essentially the domain of societies, which are free to set their own rules. Moreover, he adds that disclosure alone does not mitigate against industry interference.

Interference is sometimes insidious and difficult to quantify, as Davis notes. "There was a case about five or six years ago where a company was very interested in one of our statements and what the recommendations were going to be. The company was systematically calling all of the committee members to try and find out who was writing the statement and then tried to influence that individual by offering access to research data, and attendance at a meeting about the product. The individual came to me and we actually ceased all contact with that organization for a year."

Pullen, though, says disclosure is a good first step. "We're at a point now where everybody's in the [guideline] game and it's time to separate the high quality guidelines from anybody's guidelines so practitioners can have a sense of trust and clarity in the recommendations that they're trying to follow." - Kate Johnson, Montréal, Que.

CMAJ 2011. DOI:10.1503/cmaj.109-3841 